\title{
Monitoring and enforcement of the salt iodization programme in Tabriz, Islamic Republic of Iran: a successful experience
}

A. Kousha, ${ }^{1}$ S. Hakimi, ${ }^{1,2}$ G. Soleimanzadeh, ${ }^{1}$ N. Hashemnia ${ }^{1}$ and H. Farhadgeibi ${ }^{1}$

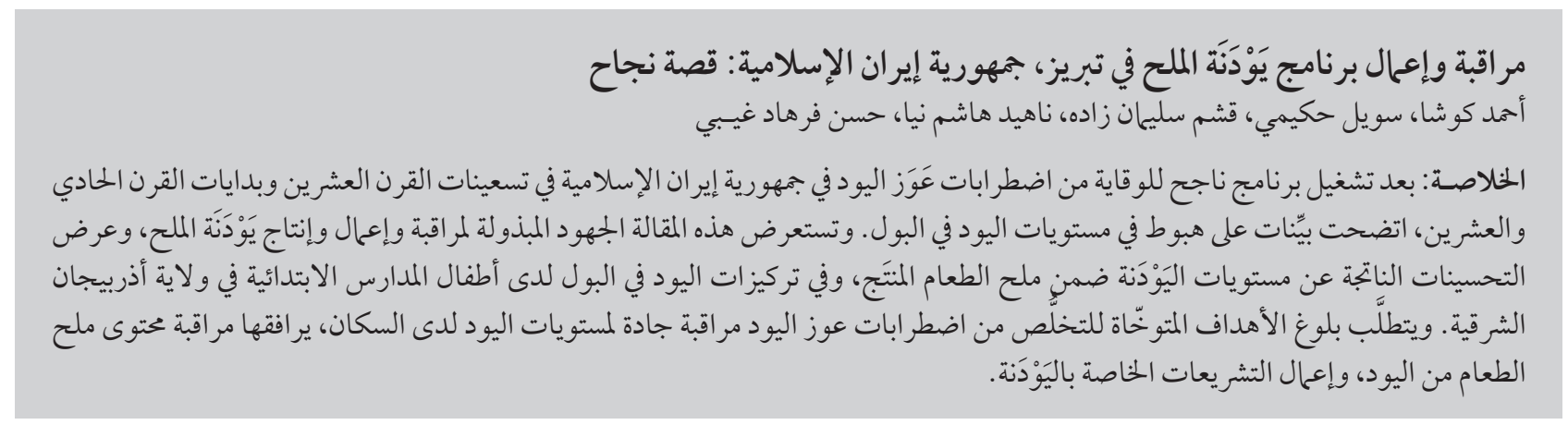

ABSTRACT After a successful programme to prevent iodine deficiency disorders in the Islamic Republic of Iran in the 1990s and early 2000s, evidence emerged that urine iodine levels in the population were falling. This paper reviews efforts to monitor and enforce the iodization of salt production and shows the resulting improvements in iodization levels of factory table salt and in urine iodine concentrations of primary-school children in East Azerbaijan province. Reaching targets for elimination of iodine deficiency disorders requires efficient monitoring of the population's iodine levels combined with monitoring of the iodine content of table salt and enforcement of iodization regulations.

Contrôle et application du programme d'iodation du sel à Tabriz (République islamique d'Iran) : une expérience réussie

RÉSUMÉ Suite au succès d'un programme visant à prévenir les troubles dus à une carence en iode en République islamique d'Iran dans les années 1990 et au début des années 2000, il est apparu que les taux d'iode urinaire dans la population décroissaient. Le présent article étudie les efforts réalisés pour contrôler et mettre en œuvre l'iodation de la production de sel et fait apparaître les améliorations qui en découlent en termes de taux d'iodation du sel de table sorti d'usine et de concentration d'iode urinaire chez les enfants d'écoles primaires dans la province d'Azerbaïdjan oriental. Afin d'atteindre les objectifs fixés en matière d'élimination des troubles dus à une carence en iode, un contrôle efficace des taux d'iode de la population et de la quantité d'iode contenue dans le sel de table ainsi que l'application d'une législation relative à l'iodation sont nécessaires. 


\section{Introduction}

Iodine-deficiency disorders (IDD) result from insufficient iodine in the environment and inadequate intake of iodine from food. Lack of iodine is the single most common cause of preventable mental retardation and brain damage in the world today $[1,2]$. Over 600 million people have goitre and 20 million have some degree of brain damage, 6 million with congenital iodine-deficiency syndrome [3].

The Islamic Republic of Iran has been recognized as an area of iodine deficiency since 1969. Extensive studies in the 1980s found goitre to be hyperendemic in many areas [4]. At that time, IDD was acknowledged as a priority health problem in the country. Because the main factor responsible for iodine deficiency is a low dietary supply of iodine [5], a national programme of iodine supplementation through iodized table salt was implemented in 1989. By 1994 more than $95 \%$ of households were consuming iodized table salt [6]. Following this massive intervention effort, the prevalence of goitre in the country fell dramatically from $68 \%$ in 1989 to $54.8 \%$ in 1996 , reaching a level of just $9.8 \%$ in 2001 [7].

Later in the 2000s, evidence started to emerge that the IDD prevention programme was failing. In East Azerbaijan province, monitoring of urinary iodine concentrations (UIC) of primaryschool children showed a sharp decrease in median UIC from $140 \mu \mathrm{g} / \mathrm{L}$ and 141 $\mu \mathrm{g} / \mathrm{L}$ in 2000 and 2001 respectively to $68 \mu \mathrm{g} / \mathrm{L}$ in 2003, while in 2004 it decreased again to reach $65 \mu \mathrm{g} / \mathrm{L}$, which is less than the optimal level of $\geq 100 \mu \mathrm{g} / \mathrm{L}$ [8]. For this reason the Public Health Deputy initiated an assessment of the causes of the rise in iodine deficiency in November 2003, combined with a public health intervention to achieve optimal levels of urinary iodine in children, including a public awareness campaign with intersectoral collaboration to enforce the salt iodization regulations.
This paper reviews the efforts to monitor and enforce the iodization of salt production and demonstrates the resulting improvements in iodization levels of factory-produced table salt and in the urinary iodine status of primaryschool children in East Azerbaijan province.

\section{Methods}

\section{Monitoring of children's urinary iodine status}

Monitoring of children's urinary iodine status was carried out as a crosssectional study. The sampling frame consisted of a list of primary schools in East Azerbaijan province. Stratified sampling was used to select 48 primary schools from rural and urban areas. We used simple random methods to select 5 schoolchildren aged 8-10 years old from each school, giving a total sample of 240 children. The proportions from rural and urban areas (34\% versus $66 \%$ ) were the same as the urban-rural population distribution in the whole of the Islamic Republic of Iran.

Urine samples were collected in disposable containers and frozen until analysis. UIC was measured by standard colorimetric methods using the speed of colour change of ammonium sulfate with arsenic acid catalysed by iodine [9]. We used the cut-offs for iodine levels recommended by the World Health Organization, United Nations Children's Fund and International Council for the Control of Iodine Deficiency Disorders (WHO/UNICEF/ ICCIDD). The median UIC for a population should be $\geq 100 \mu \mathrm{g}$ iodine per litre of urine. Mild iodine deficiency is UIC in the range 50-99 $\mu \mathrm{g} / \mathrm{L}$; moderate deficiency $20-49 \mu \mathrm{g} / \mathrm{L}$; and severe deficiency $<20 \mu \mathrm{g} / \mathrm{L}[8]$.

\section{Monitoring and enforcement of table salt iodization}

All the salt production factories in East Azerbaijan have a quality control laboratory for routine monitoring of salt levels. Technicians select samples of iodized salt during each shift and conduct chemical analyses of iodine content, humidity and purity of salt. An external assessment by the Food and Drug Institute routinely evaluates the quality of iodized salt every 3 months. In the laboratory, iodized salt is examined by standard titration methods, which are based on the interaction of potassium iodide in an acid environment and titration of iodine, which is generated by sodium thiosulfate solution [10]. The optimal recommended level of iodine in table salt for human consumption is 30 (standard deviation 10) ppm, between $51-55 \mathrm{ppm}$ is adequate, while levels < $15 \mathrm{ppm}$ and $>55 \mathrm{ppm}$ iodine are inadequate [8].

To reinforce the iodization programme the Public Health Deputy undertook a multisectoral intervention involving the laboratories of the Food and Drug Institute, the Ministry of Justice, district health networks and primary schools. This included public information about iodized salt and goitre. All salt consignments entering East Azerbaijan towns were inspected and sampled and all substandard salt consignments were destroyed. Illegal salt factories were closed. As the stability of iodine is higher in purified salt all the salt factories were obliged to use a saltwashing system.

\section{Statistical analysis}

Mean, median and standard deviation (SD) were calculated. Urinary iodine data were analysed with descriptive statistics and Student $t$-test using SPSS, version 11 software.

\section{Results}

\section{Children's urinary iodine status}

Analysis of urine samples from children showed that the median UIC was 68 $\mu \mathrm{g} / \mathrm{L}$ in 2003 and $65 \mu \mathrm{g} / \mathrm{L}$ in 2004, 
indicating mild iodine deficiency according to WHO/UNICEF/ICCIDD criteria [8]. In 2005, however, there was a sharp increase in median UIC to $107 \mu \mathrm{g} / \mathrm{L}$, above the cut-off for optimal levels $(100 \mu \mathrm{g} / \mathrm{L})$, and in 2006 there was a further slight increase to $119 \mu \mathrm{g} / \mathrm{L}$ (Figure 1). There was no significant difference between the median UIC between girls and boys from 2004- to 2006 (Figure 2) $(P>0.05)$.

In $200474.9 \%$ of our sample of children had UIC $<100 \mu \mathrm{g} / \mathrm{L}$ and $27.6 \%$ had UIC $<50 \mu \mathrm{g} / \mathrm{L}$ (Figure 3), higher than the cut-offs of $50 \%$ and $20 \%$ respectively [8]. By 2005 the percentage of children with UIC $<100 \mu \mathrm{g} / \mathrm{L}$ had fallen to $46.5 \%$, while in 2006 it was slightly lower again at $42.8 \%$.

\section{Table salt iodization levels}

The mean and median iodine content of iodized salt samples obtained from factories are shown in Table 1. In 2004 the monitoring system had become very weak and only 16 samples of salt were available for analysis from 8 factories; none of which had an optimum level of iodine; $37.5 \%$ were adequate, $37.5 \%$ were inadequate and $25.0 \%$ of

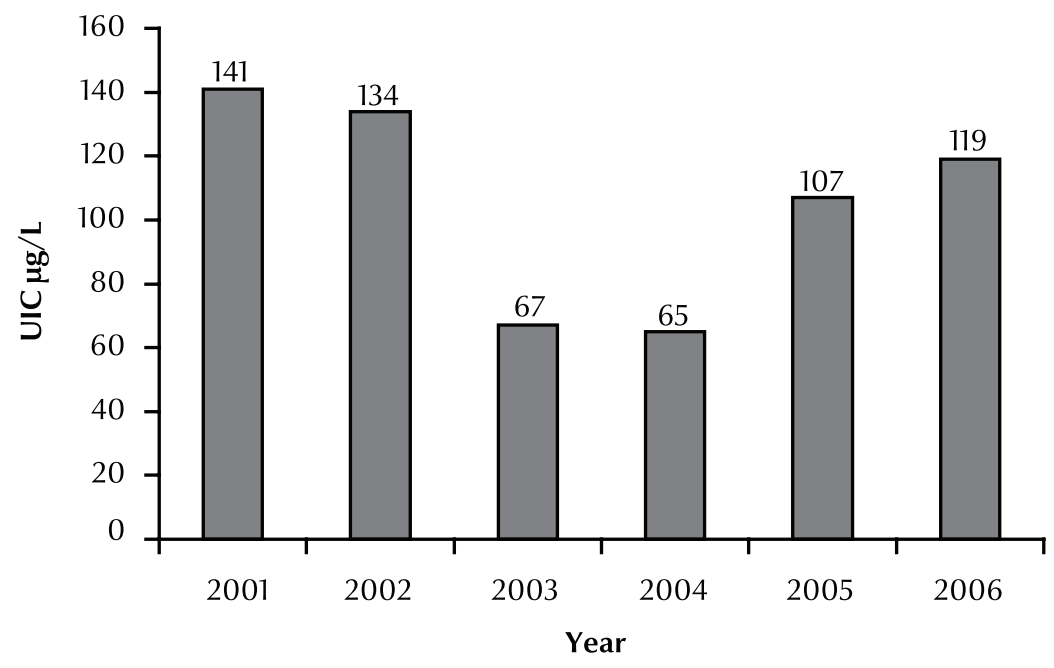

Figure 1 Trend in median urine iodine concentration (UIC) of primary-school pupils before and after the intervention

samples were completely uniodized, despite the package bearing an iodized label (Table 2). After the intervention in 2005 it is clear that the monitoring system had improved and 107 salt samples from 23 factories were analysed; $22.1 \%$ were optimum, $40.7 \%$ adequate, $26.0 \%$ inadequate and $11.2 \%$ were completely uniodized. By 2006 the number of samples obtained for analysis had increased further to 204 from 29 factories; 55.9\% had an optimum level of iodine, $25.5 \%$ adequate, $14.2 \%$ inadequate and only $4.4 \%$ of samples were uniodized.

\section{Discussion}

Iodized salt prophylaxis is the most effective way to correct iodine deficiency in a population [4]. A nationwide programme of iodine supplementation

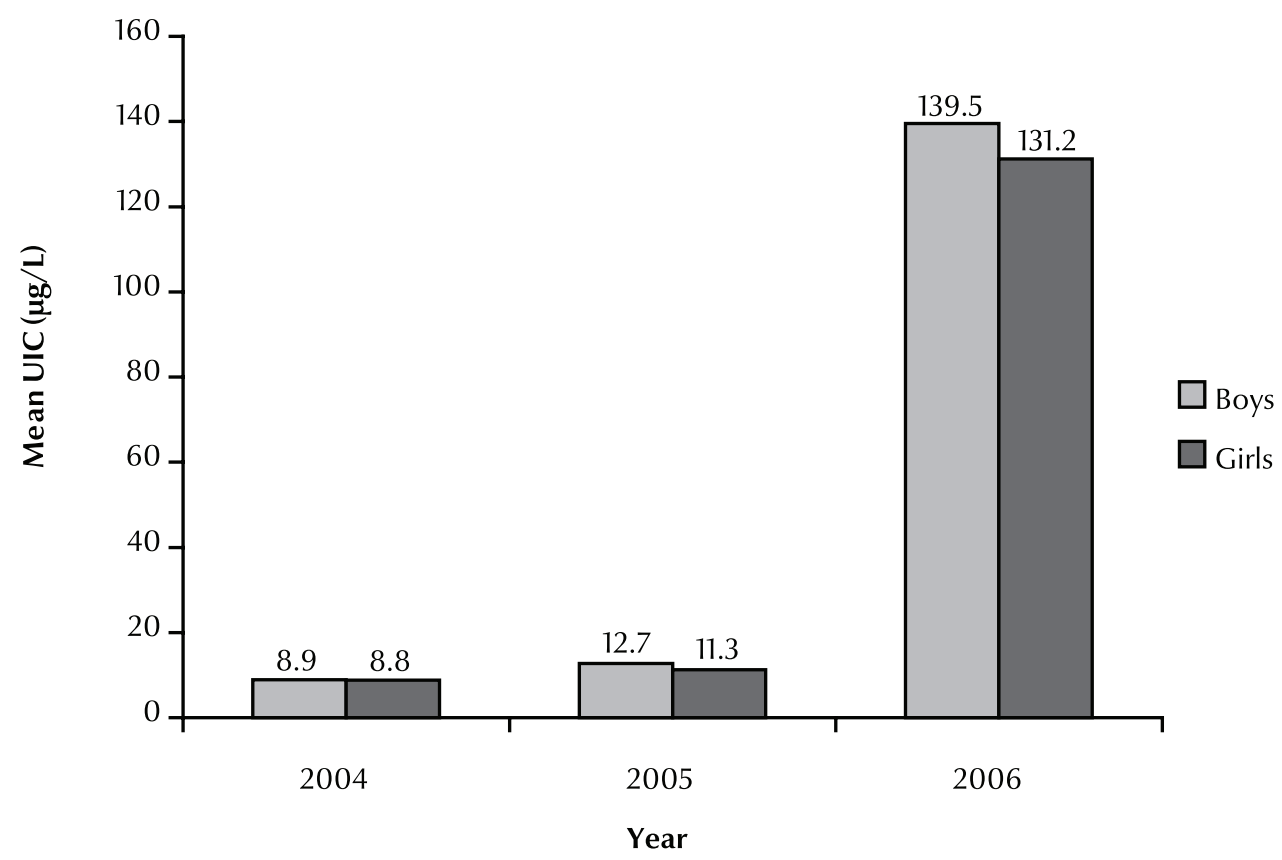

Figure 2 Mean urine iodine concentration (UIC) of boys and girls before and after the intervention 


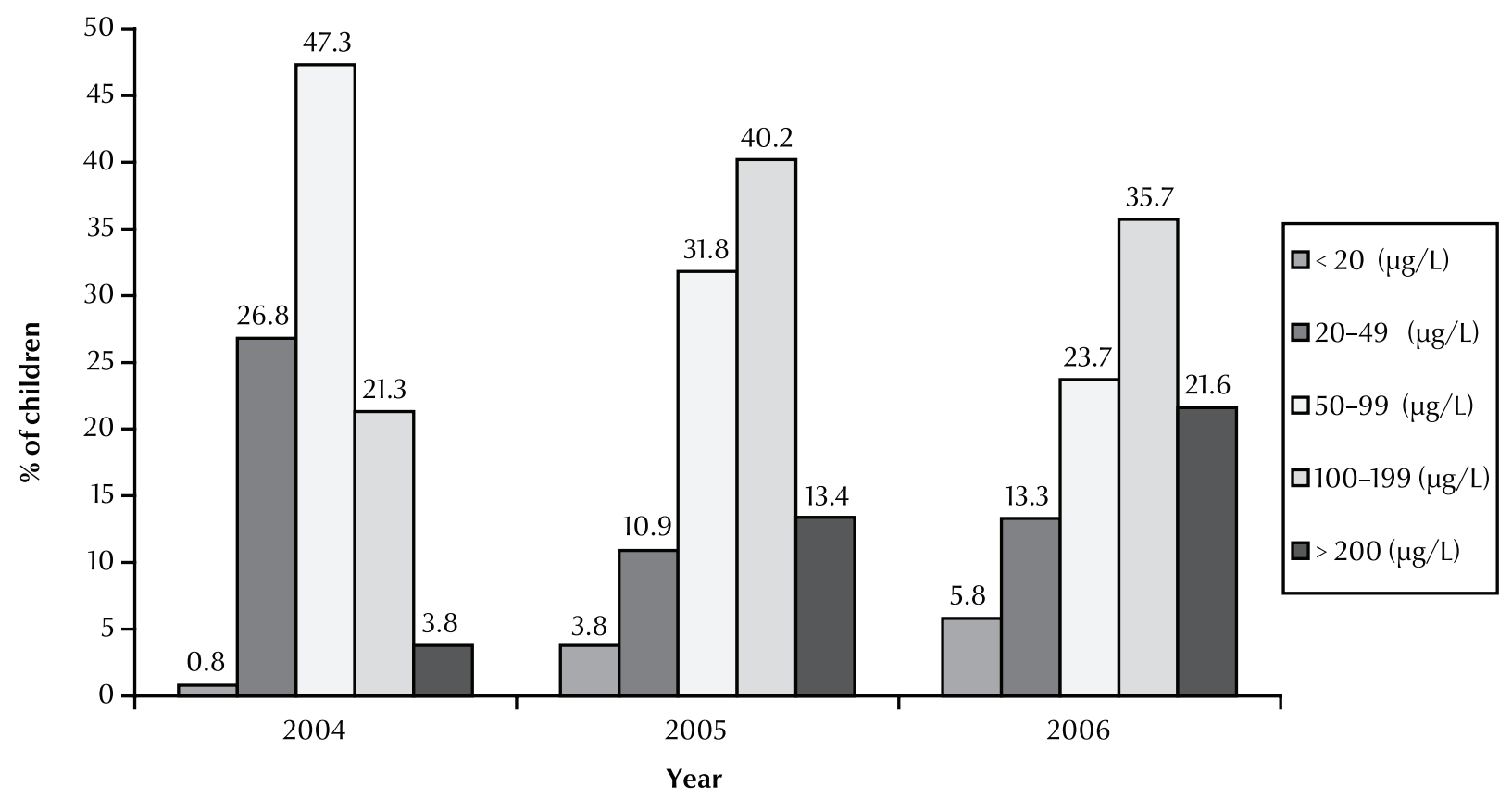

Figure 3 Distribution of median urine iodine concentration of primary-school pupils before and after the intervention

through iodized table salt was implemented in the Islamic Republic of Iran in 1989 and became mandatory for sale to households throughout the country [5]. Despite evidence that by 1994 more than $95 \%$ of households were consuming iodized table salt [6], our monitoring of population levels of

UIC, the most reliable indicator of IDD [4], showed mild iodine deficiency had re-emerged in primary-school children in East Azerbaijan in 2003 and 2004. The median UIC of our samples were $68 \mu \mathrm{g} / \mathrm{L}$ in 2003 and $65 \mu \mathrm{g} / \mathrm{L}$ in 2004. Studies have shown that schoolchildren with $\mathrm{UIC}<50 \mu \mathrm{g} / \mathrm{L}$ are at significant

$\begin{aligned} & \text { Table 1 lodine concentration in salt samples from factory production batches in } \\
& \text { the years 2004-06 }\end{aligned}$
\begin{tabular}{lcccc} 
Year & $\begin{array}{c}\text { No. of salt } \\
\text { samples }\end{array}$ & \multicolumn{2}{c}{ lodine concentration (ppm) } \\
& Mean (SD) & Median & Range \\
2004 & 16 & $12.4(9.3)$ & 12 & $0-25$ \\
2005 & 107 & $25.2(24.7)$ & 24 & $0-200$ \\
2006 & 204 & $32.4(16.7)$ & 34 & $0-140$ \\
\hline
\end{tabular}

Optimum iodine: 30 ppm; adequate: $51-55$ ppm; inadequate: $<15$ ppm and > 55 ppm (WHO/UNICEF) ICCIDD guidelines [11]).

$S D=$ standard deviation. risk of developing hypothyroidism and mental and physical retardation if iodine deficiencies are not corrected [11]. In 2004, 74.9\% of children had $\mathrm{UIC}<100 \mu \mathrm{g} / \mathrm{L}$ and $27.6 \%$ had UIC $<$ $50 \mu \mathrm{g} / \mathrm{L}$. Immediate action was needed as these values were higher than the values of $50 \%<100 \mu \mathrm{g} / \mathrm{L}$ and $20 \%<$ $50 \mu \mathrm{g} / \mathrm{L}$ according to the criteria for assessing IDD and monitoring progress towards eliminating IDD as a public health problem [8].

Concerns about the median UIC of primary-school children were reported to the authorities and an immediate campaign was started with inter-sectional collaboration and public education via the mass media to improve the situation. Our sampling results from

\begin{tabular}{|c|c|c|c|c|c|c|c|c|c|c|}
\hline \multirow[t]{3}{*}{ Year } & \multirow{3}{*}{$\begin{array}{c}\text { Factories } \\
\text { monitored } \\
\text { No. }\end{array}$} & \multirow{3}{*}{$\begin{array}{c}\text { Salt samples } \\
\text { tested } \\
\text { No. }\end{array}$} & \multicolumn{8}{|c|}{ Level of iodization of salt ${ }^{\mathrm{a}}$} \\
\hline & & & \multicolumn{2}{|c|}{$\begin{array}{l}\text { Optimum } \\
\text { (30 ppm) }\end{array}$} & \multicolumn{2}{|c|}{$\begin{array}{l}\text { Adequate } \\
\text { (15-55 ppm) }\end{array}$} & \multicolumn{2}{|c|}{$\begin{array}{c}\text { Inadequate } \\
(<\mathbf{1 5} \mathrm{ppm} \text { or }>55 \mathrm{ppm})\end{array}$} & \multicolumn{2}{|c|}{ Uniodized } \\
\hline & & & No. & $\%$ & No. & $\%$ & No. & $\%$ & No. & $\%$ \\
\hline 2004 & 8 & 16 & 0 & 0 & 6 & 37.5 & 6 & 37.5 & 4 & 25.0 \\
\hline 2005 & 23 & 107 & 45 & 22.1 & 83 & 40.7 & 53 & 26.0 & 23 & 11.2 \\
\hline 2006 & 29 & 204 & 114 & 55.9 & 52 & 25.5 & 29 & 14.2 & 9 & 4.4 \\
\hline
\end{tabular}

${ }^{a}$ WHO/UNICEF/ICCIDD cut-offs [11]. 
factories revealed that levels of table salt iodization in the province were inadequate. In 2004 none of the table salt samples from factories had optimum levels of iodine and $25.0 \%$ were completely uniodized. Only 8 factories were sampled in that year, demonstrating that the monitoring programme had become weak. Following the campaign, the number of factories tested had tripled and $22.1 \%$ of salt batches were found to be optimal and, by 2006 , $55.9 \%$ were optimal. The median IUC of primary-school children recovered to optimal levels for controlling IDD: 107 $\mu \mathrm{g} / \mathrm{L}$ in 2005 and $119 \mu \mathrm{g} / \mathrm{L}$ in 2006.

\section{Conclusions}

Our experiences show that reaching the target of eliminating IDD requires efficient monitoring of the iodine content of salt at the production site and the retail level and enforcement of existing laws. Success in raising the mean IUC of children in 2005 and 2006 was largely due to the commitment and cooperation of the Food and Drug Institute and salt producers, together with financial and technical support from the Public Health Deputy. In order to achieve global goals for elimination of IDD, iodine control and monitoring programmes need to be constantly sustained due to the fact that IDD quickly re-appears if salt iodization is interrupted. Appropriate iodized salt production technology should be available to small workplaces to enable them to produce purified salt for iodization.

\section{Acknowledgements}

We thank the parents, children and staff of the reference laboratory, our colleagues in health network 19 in East Azerbaijan province for their cooperation in the study and the Ministry of Health for providing funds.

\section{References}

1. Al-Hosani $\mathrm{H}$ et al. Prevalence of iodine deficiency disorders in the United Arab Emirates measured by raised TSH levels. Eastern Mediterranean health journal, 2003, 9(1/2):6-12.

2. Guttikonda $\mathrm{K}$ et al. Iodine deficiency in urban primary schoo children: a cross sectional study. Medical journal of Australia, 2003, 179(7):346-8.

3. Nawal A et al. lodine deficiency disorders among primaryschool children in Kafr El Sheikh, Egypt. Eastern Mediterranean health journal, 1997, 3(1):29-37.

4. Azizi $F$ et al. Effects of salted food consumption on urinary iodine and thyroid function tests in two provinces in the Islamic Republic of Iran. Eastern Mediterranean health journal, 2001, 7(1/2):115-20.

5. Sadedhipor Roudsari HR et al. Assessment of urine iodine in school children from urban and rural areas of Tehran in 2001. Pakistan journal of medical science, 2004, 20(2):131-6.

6. Ordookhani A et al. Screening for congenital hypothyroidism in the Islamic Republic of Iran: strategies, obstacles and future perspectives. Eastern Mediterranean health journal, 2002, 8(4/5):110-4.
7. Azizi F, Mehran L. Experiences in the prevention, control and elimination of iodine deficiency disorders: a regional perspective. Eastern Mediterranean health journal, 2004, 10(6):761-70.

8. World Health Organization/United Nations Children's Fund/ International Council for the Control of Iodine Deficiency Disorders. Recommended iodine levels in salt and guidelines for monitoring their adequacy and effectiveness. Geneva, World Health Organization, 1996 (WHO/NUT/96.13) (http://whqlibdoc.who.int/hq/1996/WHO_NUT_96.13.pdf, accessed 17 November 2009).

9. Benoist B et al. Iodine status world wide. WHO global database on iodine deficiency. Geneva, World Health Organization, 2004.

10. Yermakov V, Galushko S, Gerasimov G. lodized salt situational analysis in Ukraine. Kiev, Ukraine, United Nations Children's Fund, 2002.

11. Sebotsa $\mathrm{M}$ et al. Prevalence of goitre and urinary status of primary school children in Lesotho. Bulletin of the World Health Organization, 2003, 8(1):20-34. 